\title{
Covid-19: high rates of severity and death in elderly and patients with chronic diseases reinforces the importance of regular physical activity
}

\author{
Guilherme F. Speretta ${ }^{1}$ (1) $\cdot$ Richard Diego Leite ${ }^{2}$
}

Received: 21 April 2020 / Accepted: 12 July 2020 / Published online: 26 July 2020

(c) Springer-Verlag Italia S.r.l., part of Springer Nature 2020

Coronavirus disease 2019 (Covid-19) caused by Coronavirus 2 (SARS-CoV-2) has been emerging exponentially worldwide with approximately 8,261,260 confirmed cases and 445,468 deaths up to Jun 17, 2020 [1]. Although in most cases the Covid-19 symptoms are mild, the SARS-CoV-2 is transmitted easily and quickly and can overwhelm health systems [2]. Current evidence indicated that at least $15 \%$ of Covid-19 patients develop severe symptoms and need intensive care [3-5]. Noticeably, age is a factor that contributes to severe outcomes [6] and the presence of chronic diseases (CDs), in patients at any age, seems to contribute to severity and death [5]. An Italian report has described the characteristics of Covid-19 associated deaths, showing that the mean age was 78.5 and the most common pre-existing comorbidities were hypertension and diabetes [5]. Furthermore, according to data from the China outbreak, hypertension and diabetes were more prevalent in Covid-19 patients with severe (23.6 and $16.8 \%$, respectively) compared to those with nonsevere (13.3 and 5.7\%) symptoms [3].

It is well accepted that increases in visceral adipose tissue lead to metabolic alterations and chronic inflammation, increasing the risk for CDs [7]. These disturbers also negatively impact immunity from infection, vaccine efficacy [8], and may contribute to the severity of Covid-19 since evidence suggests that a subgroup of those patients have a cytokine storm syndrome (i.e. hyperinflammation) [9]. Indeed, it has been demonstrated that obesity is a risk factor

Guilherme F. Speretta

guilherme.speretta@ufsc.br

1 Department of Physiological Sciences, Biological Sciences Center, Federal University of Santa Catarina (UFSC), Rua Roberto Sampaio Gonzaga s/n, Trindade, Florianópolis, SC 88040-900, Brazil

2 Department of Sports, Centre for Physical Education and Sports, Federal University of Espírito Santo (UFES), Vitória, ES, Brazil for Covid-19 intensive care admission in patients younger than 60 years in the United States [10]. A French study also showed that the risk for invasive mechanical ventilation among Covid-19 patients was 7.36 higher for those with body mass index $(\mathrm{BMI})>35 \mathrm{~kg} / \mathrm{m}^{2}$ compared to patients with $\mathrm{BMI}<25 \mathrm{~kg} / \mathrm{m}^{2}$ [11].

No vaccines or specific drugs have been developed for Covid-19 to date. Furthermore, even countries that have adopted social isolation policies to mitigate or suppress the transmission may have a second wave of SARS-CoV-2 contamination [2]. Beyond social isolation, can behavioral interventions help to reduce Covid-19 morbidity and mortality? We believe that alterations of the contemporary lifestyle, that includes sedentarism, unhealthy food intake, and stress [7], would help to prevent severe outcomes in infected people. For instance, regular physical activity (PA) has been associated with benefits to the immune system in different populations $[12,13]$. Regular PA seems to attenuate the immune disturbers related to age (i.e. immunosenescence), particularly preventing $T$ cell remodelling. It reduces the risk of infections and improves the control of latent viral infection [12]. Higher PA levels also induce enhancements in the metabolism and the cardiovascular system in healthy individuals and people with CDs [14]. PA may induce shortterm immune adaptations and it has been attributed to an anti-inflammatory effect by the visceral fat mass reduction and/or the induction of an anti-inflammatory environment [13].

It has been recommended that active people should maintain PA as part of their routine during the Covid-19 pandemic [15]. Nevertheless, it is still unclear whether the same applies to sedentary, elderly, and people with CDs. Studies have shown that excessive PA amount or intensity induces lymphocytosis during and immediately after exercise [13]. This may lead to a transitory immune depression, although the lymphocytes levels return to basal within $24 \mathrm{~h}$ [13]. On the other hand, short moderate-intensity activities seem to 
do not promote significant acute immune depression [13]. Thus, it seems to be safe to incorporate regular moderate doses of PA as part of the routine. The American College of Sports Medicine recommends $\geq 30$ min of moderate PA on $\geq 5$ days/week. However, performing $\geq 30 \mathrm{~min}$ of PA all at once could be exhausting for people with very low PA levels [14]. For this reason, breaking up the total time throughout the day should be considered [14]. The guidelines suggest that moderate exercise should be performed between 64-76\% of maximal heart rate and/between $12-13$ on the 6-20 rating of perceived exertion Borg's Scale [14]. Importantly, in addition to immune and cardiometabolic positive effects, regular PA may protect against psychological distress [16] that has been described in different populations during the Covid-19 pandemic [17].

The Covid-19 outbreak is causing a very deleterious impact on the health and economic systems worldwide. Thus, we strongly suggest the development of studies to evaluate the impact of PA levels and other lifestyle factors on the severity and deaths in patients with Covid-19. We are aware that a healthy lifestyle, including PA, will not be the solution for the pandemic, nevertheless, it can be a valuable adjuvant acting as following. First, improving immunity, especially in elderly people, and the clinical condition of patients with CDs. Second, increasing the Covid-19 vaccine efficacy when it is available. Third, enhancing mental health. Taken together, the PA outcomes might also promote indirect effects such as less overwhelming of health systems by decreasing the number of severe cases, which also would result in significant economic benefits.

\section{Compliance with ethical standards}

Conflict of interest No conflict of interest is declared by the author(s).

\section{References}

1. John Hopkins University (2020) Coronavirus COVID-19 Global Cases by the Center for Systems Science and Engineering (CSSE) at Johns Hopkins University (JHU). https://coronavirus.jhu.edu/ map.html

2. Ferguson NM et al (2020) Report 9: impact of non-pharmaceutical interventions (NPIs) to reduce COVID19 mortality and healthcare demand. https://doi.org/10.25561/77482

3. Guan WJ et al (2020) Clinical characteristics of coronavirus disease 2019 in China. N Engl J Med. https://doi.org/10.1056/ NEJMoa2002032
4. Zhang JJ et al (2020) Clinical characteristics of 140 patients infected with SARS-CoV-2 in Wuhan, China. Allergy. https:// doi.org/10.1111/all.14238

5. CSG, COVID-19 Surveillance Group (2020) Characteristics of COVID-19 patients dying in Italy. Instituto Superiore di Sanitá, Rome

6. Verity R et al (2020) Estimates of the severity of coronavirus disease 2019: a model-based analysis. Lancet Infect Dis. https:// doi.org/10.1016/S1473-3099(20)30243-7

7. Despres JP, Lemieux I (2006) Abdominal obesity and metabolic syndrome. Nature 444(7121):881-887. https://doi.org/10.1038/ nature 05488

8. Andersen CJ, Murphy KE, Fernandez ML (2016) Impact of obesity and metabolic syndrome on immunity. Adv Nutr 7(1):66-75. https://doi.org/10.3945/an.115.010207

9. Mehta P et al (2020) COVID-19: consider cytokine storm syndromes and immunosuppression. Lancet 395(10229):1033-1034. https://doi.org/10.1016/S0140-6736(20)30628-0

10. Lighter $J$ et al (2020) Obesity in patients younger than 60 years is a risk factor for Covid-19 hospital admission. Clin Infect Dis. https://doi.org/10.1093/cid/ciaa415

11. Simonnet A et al (2020) High prevalence of obesity in severe acute respiratory syndrome coronavirus-2 (SARS-CoV-2) requiring invasive mechanical ventilation. Obesity (Silver Spring). https ://doi.org/10.1002/oby.22831

12. Duggal NA et al (2019) Can physical activity ameliorate immunosenescence and thereby reduce age-related multi-morbidity? Nat Rev Immunol 19(9):563-572. https://doi.org/10.1038/s4157 7-019-0177-9

13. Walsh NP et al (2011) Position statement. Part one: immune function and exercise. Exerc Immunol Rev 17:6-63

14. Garber CE et al (2011) American College of Sports Medicine position stand. Quantity and quality of exercise for developing and maintaining cardiorespiratory, musculoskeletal, and neuromotor fitness in apparently healthy adults: guidance for prescribing exercise. Med Sci Sports Exerc 43(7):1334-1359. https://doi. org/10.1249/MSS.0b013e318213fefb

15. Chen $\mathrm{P}$ et al (2020) Coronavirus disease (COVID-19): The need to maintain regular physical activity while taking precautions. J Sport Health Sci 9(2):103-104. https://doi.org/10.1016/j. jshs.2020.02.001

16. Nakagawa T et al (2020) Regular moderate- to vigorous-intensity physical activity rather than walking is associated with enhanced cognitive functions and mental health in young adults. Int J Environ Res Public Health. https://doi.org/10.3390/ijerph17020614

17. Zhu S et al (2020) The immediate mental health impacts of the COVID-19 pandemic among people with or without quarantine managements. Brain Behav Immun. https://doi.org/10.1016/j. bbi.2020.04.045

Publisher's Note Springer Nature remains neutral with regard to jurisdictional claims in published maps and institutional affiliations. 